\title{
CrossFit across Three Platforms: Using Social Media to Navigate Niche Sport Challenges
}
Authors' contribution:
A) conception and design of the study
B) acquisition of data
C) analysis and interpretation of data
D) manuscript preparation
E) obtaining funding

\author{
Sun J. Kang ${ }^{1 \text { A-C }}$, Jason A. Rice ${ }^{\text {A-C }}$, Marion E. Hambrick ${ }^{3 \text { A-C, }}$ \\ Chulhwan $\mathrm{Choi}^{4 \mathrm{D}}$ \\ ${ }^{1}$ Manchester University, Manchester, USA \\ ${ }^{2}$ North Central College, Naperville, USA \\ ${ }^{3}$ University of Louisville, Louisville, USA \\ ${ }^{4}$ Kyung Hee University, Seoul, Republic of Korea
}

ABSTRACT

\begin{abstract}
Niche sports have limited opportunities to promote their sport offerings via traditional communication channels and may rely upon alternatives such as social media to accomplish their marketing goals (Puchan, 2004). Williams and Chinn (2010) developed a relationship marketing conceptual framework to examine social media usage and marketing within a sports context. This study used the framework with the burgeoning sport of CrossFit and examined three primary organizational relationshipmarketing activities: (a) Information, (b) Interaction, and (c) Promotion. The purpose of this study was to investigate the use of social media by key members of the CrossFit community. The study addressed the following research questions: RQ1. What are the usage categories similarities and differences observed across the social media platforms? RQ2. What are the group usage similarities and differences observed across the social media platforms? and RQ3. What are the group usage similarities and differences observed across the usage categories? A content analysis of 5,565 Twitter, Facebook, and YouTube messages was used to explore these activities. The CrossFit social media users-CrossFit Games, regions, boxes, athletes, and sponsors-used the platforms primarily to provide information about the sport and interact with the community, while promotion was employed less frequently. CrossFit and other niche sports can use social media to provide information and build community within their sports, before attempting to create online communities and promote their products.
\end{abstract}

KEYWORDS $\quad$ CrossFit, relationship marketing, social media

\section{CrossFit across three platforms: using social media to navigate niche sport challenges}

The notion of achieving a healthy and active lifestyle has altered the way people approach sport and fitness, and contemporary trends have blurred the lines between the two. An industry leader in the transition from conventional fitness to sport is CrossFit, one of the fastest growing participant sports (Rishe, 2011). CrossFit is a strength and conditioning program that involves cardiovascular exercise combined with gymnastics and weightlifting movements (Benjamin, 2012), featuring timed elements and ranked competitions. Since its introduction in 2007, participation in the CrossFit Games, the sport's premier series event, has exploded from 26,000 participants in 2010 to over 138,000 in 2013 and 209,585 in 2014 (Achauer, 2014). From these numbers it appears CrossFit has been successful in creating awareness about the sport and driving participation gains. 
Of particular interest to sport marketers is how this niche sport has generated a unique culture of fitness, built membership, produced worldwide events, and developed a brand with a devoted following in such a limited time. Niche sports are distinct from mainstream sports appealing to the public as popular sports such as football, basketball, baseball, hockey, and golf (Greenhalgh, Simmons, Hambrick, \& Greenwell, 2011). Typically, the niche sports include "sports like tennis, lacrosse, bowling, fishing, curling, horse racing, and action or extreme sports like skateboarding" that are lifestyle sports (Miloch \& Lambrecht, 2006, p.147). Crossfit is one of the newest trending lifestyle sport that provides health benefit encompassing various types of exercise and training. This study will examine one area which may contribute to this trend, how members of this niche sport community use social media. For niche sports, reduced accessibility often translates into less media coverage and fewer sponsorship opportunities. To overcome such challenges, these sports must seek creative ways beyond traditional media outlets to connect with consumers and disseminate information about their products (Greenhalgh et al., 2011).

Technological advances in communications and media have opened the doors for niche sports to introduce and showcase their offerings to a larger audience. The Internet provides access to information on a variety of activities, and niche sports are driving the growth of online sports delivery (Rozov, 2008). Social media platforms such as Facebook and Twitter can give sports organizations opportunities to share information with and gather it from their current and future consumers. Leveraging the Internet and social media represents a low-cost option to attract and retain fans (Greenhalgh et al., 2011; Puchan, 2004). CrossFit has taken advantage of these platforms to increase visibility and draw connections among its various stakeholders. These platforms are also used to connect fans with athletes and affiliate gyms with members, providing useful community information, and promote relevant products and events.

\section{Social media and relationship marketing in sports}

Social media usage represents a compelling topic, and researchers have rapidly increased their exploration of social media usage within sports (Pedersen, 2014). They initially focused on professional athletes (Clavio \& Kian, 2010; Frederick, Lim, Clavio, Pedersen, \& Burch, 2014), sports journalists (Kian \& Murray, 2014), and sports fans (Clavio \& Walsh, 2013; O’Hallarn \& Shapiro, 2014; Sanderson \& Emmons, 2014). While much of the initial research concentrated primarily on individual users, a growing number of studies have examined how sports organizations use these same platforms, among various teams, leagues, and related entities (Coddington \& Holton, 2014; Zimmerman, Clavio, \& Lim, 2011). Their research revealed social media platforms frequently are used to create and disseminate information about individual sports, players, and teams (Mahoney, Hambrick, Svensson, \& Zimmerman, 2013; Miranda, Chamorro, Rubio, \& Rodriguez, 2014), but are used less often to promote products and generate revenue streams (Hambrick \& Kang, 2014; Wallace, Wilson, \& Miloch, 2011).

As such, social media represents a viable mechanism for niche sports. With their limited media coverage, these sports often face challenges in terms of creating visibility and attracting fans and sponsors (Greenhalgh et al., 2011). Researchers have identified a positive relationship between familiarity with a sport and sport consumption behaviors (Bennett, Henson, \& Zhang, 2012). Thus, in efforts to increase their visibility and promotional efforts, niche sports may follow the suggestions of researchers and offer a more accessible environment for fans via their websites and social media platforms such as Facebook, Twitter, and YouTube (Greenhalgh et al., 2011; Puchan, 2004). These platforms provide opportunities for people to communicate and share ideas, experiences, and knowledge (Bulmer \& DiMauro, 2010). They also give niche sports a way to disseminate information to fans and participants, in addition to creating a means for non-fans to become familiar with their respective sports rules, athletes, and product offerings.

These informational and promotional activities are part of relationship marketing, which Grönroos (2004) described as a process initiated via transactions between organizations and consumers. Within a sports context, relationship marketing may begin when a consumer buys something from a sports organization, such as a single 
ticket to an event or access to their facilities. Some organizations may view this purchase as a one-time transaction; however, with relationship marketing, organizations can identify ways to develop and extend their relationships with consumers over time.

Relationship marketing stresses the need to create these ongoing connections in a sustainable fashion by emphasizing three components: (a) communication, (b) interaction, and (c) value (Grönroos, 2004). Williams and Chinn (2010) argued that social media platforms could aid this process, specifically within sports contexts. Platforms such as Facebook and Twitter readily lend themselves to two-way communications. Rather than simply advertising an event in a newspaper or on the radio, sport organizations can use social media to engage in continued conversations with fans: for example, using Twitter to promote the event in advance, provide updates throughout the event, and solicit feedback from attendees after the event. Utilizing social media in this way gives organizations an opportunity to engage in interactive conversations with consumers. They may in turn perceive value, the third component of relationship marketing, through this communication as they learn more about the organization and take part in shared experiences, which can lead to future connections.

Social media represents an important component for sports organizations seeking to enhance their relationship marketing efforts. The platforms may be used based upon an organization's marketing strategies and objectives. The previous studies identified several ways that social media platforms can be employed in a relationship marketing context, and three primary activities emerged from their findings: (a) information, (b) interaction, and (c) promotion. First and foremost, these platforms can be used as communication tools to disseminate information about the organization, whether news about the players, games, or even activities and events taking place off the playing field (Coddington \& Holton, 2014; Hambrick \& Kang, 2014). Next, interaction exists when organizations post content or communicate with fans, and prompt fans to do the same. In this way, fans have the opportunity to converse with the sport entity and share their thoughts and experiences. These combined activities can create interaction or a communal environment within the social media realm (Abeza, O'Reilly, \& Reid, 2013; O'Shea \& Alonso, 2011). Finally, promotion reflects the use of social media to generate revenues through sales of tickets and merchandise. While this component was used less frequently among the examined sport organizations, it remains an important initiative for those seeking to create sustainable and profitable entities (Pronschinske, Groza, \& Walker, 2012; Waters, Burke, Jackson, \& Buning, 2011).

Effective use of social media platforms can help organizations highlight these three areas by developing and encouraging two-way interactions with their consumers over time (Williams \& Chinn, 2010). While past research has focused on more mainstream sports in mature life cycle stages, the current study continued this examination by exploring relationship marketing from the perspective of the growing niche sport CrossFit. The sport mainly utilizes two social media platforms-Twitter and Facebook. YouTube is also used by the organization but in a more limited capacity, with one YouTube CrossFit channel amalgamating the majority of "official" videos. However, the niche sport can combine the three platforms to create an effective relationship marketing strategy and help the sport promote its brand, participants, and sponsors.

The previous studies demonstrated the importance of social media and relationship marketing and the presence of the three related activities within a single platform. Yet it is important to consider potential differences among platforms. Williams and Chinn (2010) noted that organizations should match their objectives and intended messages with the appropriate platforms, and O'Shea and Alonso (2011) stressed the need to have consistent messages when using multiple outlets. Few studies have examined multiple platforms simultaneously to assess how they can be used most effectively in combination to achieve individual and organizational goals. In order to understand how a niche sport such as CrossFit has taken advantage of multiple social media platforms for relationship marketing purposes, this study examined content shared across the three main platforms used and promoted within the sport's community.

The purpose of this study was to investigate the use of social media by key members of the CrossFit community. The study addressed the following research questions: RQ1. What are the usage categories similarities and 
differences observed across the social media platforms?, RQ2. What are the group usage similarities and differences observed across the social media platforms?, and RQ3. What are the group usage similarities and differences observed across the usage categories?

\section{Method}

Content analysis has been used to examine social media and relationship marketing within sports (Hambrick \& Kang, 2014; Wallace et al., 2011; Waters et al., 2011) and was incorporated in this study to better understand how the social media platforms Twitter, Facebook, and YouTube were used with CrossFit groups for the relationship marketing activities of; information, interaction, and promotion.

\section{Data Collection}

To gain a comprehensive understanding of the CrossFit community's social media usage, the study collected data from two distinct sources: (a) official Crossfit owned or affiliated entities and (b) high profile athletes in the sport. Purposive sampling was used with both sources to ensure the collected data represented the unique segments of the CrossFit community.

Their social media activity was examined across Twitter, Facebook, and YouTube. Data were collected over a three-month period between November 1, 2012, and January 20, 2013. Initially, a total of 5,150 messages were collected, which included data from sponsors. For the organizational data (i.e., CrossFit Games, CrossFit Kids, CrossFit Regions, and gyms/boxes), a total of 2,323 messages posted on Twitter, Facebook, and YouTube were captured during the data collection period. For the individual or athlete data, a total of 1,710 messages from Twitter and 364 messages from Facebook were initially collected from the male athlete group. In addition, 600 tweets and 236 messages from Facebook were collected from the female athlete group. To create balance between the two athlete groups, messages from the male athlete group were sampled using systematic random sampling method by drawing every fourth message from the data, while the complete collection of tweets and messages from the female athlete group was used. Additionally, the sponsor data were removed from the initial analysis, as this group was deemed ancillary to the CrossFit community. In the final sample, a total of 3,950 cases were captured for analysis: 2,431 messages from Twitter; 1,295 messages from Facebook; and 224 videos from YouTube.

The data were classified into three primary categories (Information, Interaction, and Promotion) that emerged from the sports-related social media relationship marketing literature. A fourth and final category, Content, was also added; (a) Information includes a discussion of sport- or team-specific topics related to CrossFit such as daily nutrition, fitness regimens, workout times, training techniques, and athlete updates, (b) Interaction represents shared conversations among the CrossFit groups and their social media followers, (c) Promotion focuses on revenue generation through activities such as ticket and merchandise sales, and (d) Content captures social media activity that emphasizes photographs, videos, website links, and other visual content not readily classified into one of the three previous categories.

Two researchers initially coded a subset of the data, compared their results, and finalized the codebook and category operationalization. The data subset was returned to the larger sample, and the researchers independently coded the entire dataset. Interrater reliability analysis was conducted using Cohen's kappa statistic to assess coding consistency between the two researchers and resulted in the following: Information $\kappa$ $=.82$, Interaction $\kappa=.85$, Promotion $\kappa=.79$, Content $\kappa=.86$. For exploratory research, .70 is deemed an acceptable minimum kappa value (Lombard, Snyder-Duch, \& Bracken, 2002). 


\section{Data Analysis}

Through SPSS 20.0, frequencies were calculated to provide an overview of the general social media usage within the CrossFit setting. Chi-square analyses addressed the research questions regarding potential usage similarities and differences among the CrossFit groups and three social media platforms.

\section{Results}

The social media content by category revealed that the majority of messages were categorized as Information $(1,768,44.8 \%$ of the total messages), followed by Interaction (1,239, 31\%), Content (864, 21.9\%), and Promotion (79, 2\%) (Table 1).

Table 1. Social media category by platform

\begin{tabular}{clccccc}
\hline \multirow{2}{*}{ Platform } & & \multicolumn{5}{c}{ Social Media Category } \\
\cline { 3 - 7 } & & Interaction & Information & Promotion & Content & Total \\
\hline \multirow{3}{*}{ Twitter } & Number of Messages & 1,154 & 486 & 44 & 747 & 2,431 \\
& \% within Group & 47 & 20 & 2 & 31 & 100 \\
& \% within Category & 93 & 27 & 56 & 86 & 62 \\
& Number of Messages & 82 & 1,069 & 27 & 117 & 1,295 \\
Facebook & \% within Group & 6 & 83 & 2 & 9 & 100 \\
& \% within Category & 7 & 60 & 34 & 0 & 33 \\
& Number of Messages & 3 & 213 & 8 & 0 & 224 \\
YouTube & \% within Group & 1 & 95 & 14 & 0 & 100 \\
& \% within Category & 0 & 1,768 & 79 & 864 & 6 \\
& Number of Messages & 1,239 & 45 & 2 & 22 & 100 \\
& \% within Group & 31 & 100 & 100 & 100 & 100 \\
\hline
\end{tabular}

Source: own study.

Information included updates about events as well as details about training for and competing in the sport with messages. Interaction incorporated messages traded among the groups as well as with their followers. Content messages showcased pictures and links to websites. Promotion messages highlighted the CrossFit Games and related activities or events.

\section{What are the usage categories similarities and differences observed across the social media platforms?}

Comparing categories by platforms revealed statistically significant differences, where $X^{2}=1634.187, d f=6, p$ $<.001$. The majority of Twitter messages were categorized as Interaction $(1,154,47.5 \%)$, followed by Content (747, 30.7\%), Information (486, 20.0\%), and Promotion (44, 1.8\%) (Table 1). The majority of Facebook messages were categorized as Information $(1,069,82.5 \%)$, followed by Content $(117,9.0 \%)$, Interaction ( 82 , $6.3 \%$ ), and Promotion (27, 2.1\%). Finally, most of the YouTube content was categorized as Information (213, $95.1 \%)$, followed by Promotion (8, 3.6\%), Interaction (3,1.3\%), and Content $(0,0.0 \%)$.

\section{What are the group usage similarities and differences observed across the social media platforms?}

Comparing the groups by social media platforms revealed statistically significant differences, where $X^{2}=$ 1703.417, $d f=10, p<.001$. The CrossFit Games and events used a relatively even split approach with Twitter (467, 45.5\%), Facebook (335, 32.7\%), and YouTube (224, 21.8\%). The regions used Facebook more frequently 
(77, 70.6\%) in comparison to Twitter (32, 29.4\%). The boxes primarily used Twitter (905, 76.2\%) to disseminate messages, followed by Facebook (283, 24\%). For individuals, the female athletes gravitated toward Twitter $(600,71.8 \%)$ with some Facebook usage $(236,28.2 \%)$. A similar usage pattern was found among the male athletes with Twitter $(427,54.0 \%)$ and Facebook (364, 46.0\%) (Table 2). (Notably, every fourth Twitter message posted by the males was included in the sample. These individuals in actuality posted 1,710 Twitter messages during this time period, a considerable amount of content in comparison to their female counterparts).

Table 2. Social media activity by user group

\begin{tabular}{|c|c|c|c|c|c|}
\hline \multirow[t]{2}{*}{ User group } & & \multicolumn{4}{|c|}{ Social Media Platform } \\
\hline & & Twitter & Facebook & YouTube & Total \\
\hline \multirow[t]{3}{*}{ Games/Events } & Number of Messages & 467 & 335 & 224 & 1,026 \\
\hline & $\%$ within Group & 46 & 33 & 22 & 100 \\
\hline & $\%$ within Platform & 19 & 26 & 100 & 18 \\
\hline \multirow[t]{3}{*}{ Regions } & Number of Messages & 32 & 77 & 0 & 109 \\
\hline & $\%$ within Group & 29 & 71 & 0 & 100 \\
\hline & $\%$ within Platform & 1 & 6 & 0 & 3 \\
\hline \multirow[t]{3}{*}{ Gyms/Boxes } & Number of Messages & 905 & 283 & 0 & 1,188 \\
\hline & $\%$ within Group & 76 & 24 & 0 & 100 \\
\hline & $\%$ within Platform & 37 & 22 & 0 & 30 \\
\hline \multirow[t]{3}{*}{ Female Athletes } & Number of Messages & 600 & 236 & 0 & 836 \\
\hline & $\%$ within Group & 72 & 28 & 0 & 100 \\
\hline & $\%$ within Platform & 25 & 18 & 0 & 21 \\
\hline \multirow[t]{3}{*}{ Male Athletes } & Number of Messages & 427 & 364 & 0 & 791 \\
\hline & $\%$ within Group & 54 & 46 & 0 & 100 \\
\hline & $\%$ within Platform & 18 & 28 & 0 & 20 \\
\hline \multirow[t]{3}{*}{ Total } & Number of Messages & 2,431 & 1,295 & 224 & 3,950 \\
\hline & $\%$ within Group & 62 & 33 & 6 & 100 \\
\hline & $\%$ within Platform & 100 & 100 & 100 & 100 \\
\hline
\end{tabular}

Source: own study.

Organizational versus individual users. In addition, the cases were analyzed to assess potential differences among organizations (CrossFit entities and boxes) versus individuals (athletes). Comparing the Facebook usage between the organizational and individual users revealed statistically significant differences, where $X^{2}=27.31$, $d f=9, p=.001$. On the contrary, comparing organizational and individual users for Twitter usage did not reveal statistically significant differences, where $X^{2}=4.78, d f=9, p=.853$. When combining Twitter and Facebook usage for the organizations and comparing them against the combined data of individuals, the results revealed statistically significant differences, where $X^{2}=189.92, d f=9, p<.001$.

Usage differences among the platforms. Further examining how the organizations and individuals used the different platforms revealed interesting results. Comparing the Twitter and Facebook usage for the organizations revealed no statistically significant differences, where $X^{2}=8.280, d f=9, p=.506$. However, comparing Twitter usage and Facebook usage for the individuals revealed statistically significant differences, where $X^{2}=918, d f$ $=9, p<.001$. For YouTube, a statistically significant difference was observed when comparing organizational YouTube usage with organizational Facebook usage, where $X^{2}=21.38, d f=6, p=.002$; whereas comparing this YouTube organizational usage in comparison to organizational Twitter usage did not reveal statistical differences, where $X^{2}=4.56, d f=6, p=.602$. In addition, YouTube's comparisons with both the Twitter and 
Facebook usage for individuals were not significantly different (Twitter $X^{2}=4.59, d f=6, p=.597$; Facebook $\left.X^{2}=4.59, d f=6, p=.576\right)$.

\section{What are the group usage similarities and differences observed across the usage categories?}

Comparing the groups by categories revealed statistically significant differences, where $X^{2}=589.695, d f=15$, $p<.001$. For the CrossFit Games and events, most of their messages focused on Information (520, 50.7\%), followed by Content (256, 25.0\%), Interaction (209, 20.4\%), and Promotion (41, 4.0\%). For the regions, Information represented the largest category $(54,49.5 \%)$, followed by Interaction and Content $(26,23.9 \%)$ for each category, respectively, and Promotion (3, 3\%). For the boxes, Information (479, 40\%) and Interaction (451, $38.0 \%)$ reflected the largest percentage of messages, followed by Content $(254,21.4 \%)$ and Promotion (4, $0.3 \%)$. Finally, for individuals, female athletes exhibited a preference for Interaction $(349,421.7 \%)$ and Information $(328,39.2 \%)$, followed by Content $(140,16.7 \%)$ and Promotion $(19,2.3 \%)$. Male athletes on the contrary exhibited a preference for Information (387, 48.9\%), followed by Interaction (204, 25.8\%), Content $(188,23.8 \%)$, and Promotion (12, 1.5\%) (Table 3).

Table 3. Social media activity by user group

\begin{tabular}{|c|c|c|c|c|c|c|}
\hline \multirow[t]{2}{*}{ User group } & & \multicolumn{5}{|c|}{ Social Media Category } \\
\hline & & Interaction & Information & Promotion & Content & Total \\
\hline \multirow[t]{3}{*}{ Games/Events } & Number of Messages & 209 & 520 & 41 & 256 & 1,026 \\
\hline & $\%$ within Group & $20 \%$ & $51 \%$ & $4 \%$ & $25 \%$ & $100 \%$ \\
\hline & $\%$ within Category & $15 \%$ & $18 \%$ & $52 \%$ & $22 \%$ & $18 \%$ \\
\hline \multirow[t]{3}{*}{ Regions } & Number of Messages & 26 & 54 & 3 & 26 & 109 \\
\hline & $\%$ within Group & $24 \%$ & $50 \%$ & $3 \%$ & $24 \%$ & $100 \%$ \\
\hline & $\%$ within Category & $2 \%$ & $2 \%$ & $4 \%$ & $2 \%$ & $2 \%$ \\
\hline \multirow[t]{3}{*}{ Gyms/Boxes } & Number of Messages & 451 & 479 & 4 & 254 & 1,188 \\
\hline & $\%$ within Group & $38 \%$ & $40 \%$ & $0 \%$ & $21 \%$ & $100 \%$ \\
\hline & $\%$ within Category & $32 \%$ & $16 \%$ & $5 \%$ & $22 \%$ & $21 \%$ \\
\hline \multirow[t]{3}{*}{ Female Athletes } & Number of Messages & 349 & 328 & 19 & 140 & 836 \\
\hline & $\%$ within Group & $42 \%$ & $39 \%$ & $2 \%$ & $17 \%$ & $100 \%$ \\
\hline & $\%$ within Category & $25 \%$ & $11 \%$ & $24 \%$ & $12 \%$ & $15 \%$ \\
\hline \multirow[t]{3}{*}{ Male Athletes } & Number of Messages & 204 & 387 & 12 & 188 & 791 \\
\hline & $\%$ within Group & $26 \%$ & $49 \%$ & $2 \%$ & $24 \%$ & $100 \%$ \\
\hline & $\%$ within Category & $14 \%$ & $13 \%$ & $15 \%$ & $16 \%$ & $14 \%$ \\
\hline \multirow[t]{3}{*}{ Total } & Number of Messages & 1,239 & 1,768 & 79 & 864 & 3,950 \\
\hline & $\%$ within Group & $31 \%$ & $45 \%$ & $2 \%$ & $22 \%$ & $100 \%$ \\
\hline & $\%$ within Category & $100 \%$ & $100 \%$ & $100 \%$ & $100 \%$ & $100 \%$ \\
\hline
\end{tabular}

Source: own study.

Including sponsor social media usage. The initial results demonstrated that the groups were primarily utilizing social media resources in a similar manner. Subsequently, the researchers re-added CrossFit sponsors for further analysis. Just as athletes play an integral role in a niche sport's attempts to increase awareness and growth, sponsors have the same ability. Well-aligned sponsors understand their sponsorship will benefit from a sport's growth, and thus make attempts to assist the sport's organizational goals. The researchers identified five primary CrossFit Games sponsors (i.e., Rogue Fitness, Reebok, GNC, FRS, and Vita Coco) and collected a total of 1,615 messages from their respective Twitter and Facebook pages. At the time of data collection, no evidence of CrossFit videos was found on any of the sponsor's official YouTube sites, and thus was not included in the analysis. Results indicated that sponsor social media usage was significantly different than the other groups, 
and this finding supported the decision to remove sponsor data from the initial analysis. When comparing sponsor usage categories and organizational data on both Twitter and Facebook, the results were significant, where $X^{2}=118.95, d f=6, p<.001$. In detail, the majority of their messages were Information $(1,154,71.5 \%)$, followed by Content $(281,17.4 \%)$, Interaction $(180,11.1 \%)$, and Promotion $(0,0.0 \%)$. Looking more closely at each sponsor's tweets and Facebook messages, only one sponsor (Rogue Fitness) promoted CrossFit regularly within its messaging. Other sponsors displayed limited use of their CrossFit relationship, and instead focused their attention on disseminating their brand-specific information on the evaluated social media platforms.

\section{Discussion and conclusions}

Many of the previous social media relationship marketing studies focused on a single sports team (Coddington \& Holton, 2014) or sports league (Pronschinske et al., 2012; Waters et al., 2011). They often selected one social media platform, most commonly Facebook, to explore in more detail (Pronschinske et al., 2012; Wallace et al., 2011; Waters et al., 2011). Conversely, this study examined CrossFit as a niche sport and the use of social media among its community members across three platforms - Twitter, Facebook, and YouTube. The inclusion of multiple groups and platforms in this study provides a more comprehensive analysis and extends the research related to relationship marketing within sports. The findings revealed usage differences in the platforms and messages disseminated through them.

\section{Theoretical implications}

Information. Previous research has documented the extensive use of the information-sharing component among mainstream and niche sports alike (Pronschinske et al., 2012; Waters et al., 2011). Similar activities occurred within the CrossFit community as the organizational and individual members offered an array of information about various events, training and competing in the sport.

These awareness and attraction activities may represent a necessary first step before niche sport organizations can engage in more interactive and promotional opportunities, which by their nature dictate that a minimum number of fans actively take part in the sports as participants and competitors. Within CrossFit, we witnessed this information sharing as part of developing awareness about the sport. The CrossFit events and regions produced at least $50 \%$ of their messages within this category. As a sport still in its growth stage, CrossFit as an organization has utilized the ability of social media platforms to disseminate information to the community. Individual athletes, while less active than the events and regions within this category, are still very involved in the information sharing process. The high-profile athletes are both consumers of the CrossFit product and valuable promoters of the CrossFit brand.

Interaction. The CrossFit groups in this study repeatedly offered social media messages focused on Interaction. Relationship marketing studies have documented sports organizations using social media platforms to create a sense of community via online interaction, and previous studies have noted the advantages of these ongoing conversations. Platforms such as Twitter naturally lend themselves to increased interaction among organizations and their followers (Williams \& Chinn, 2010). This exchange facilitates the ready dissemination of information among readers throughout the platform and increases the amount of "touches" an individual has with the sport. In this study, Interaction messages were most often posted on Twitter. Many of these messages were direct responses from the various CrossFit groups and individuals to their followers. The female athletes were the only group to favor Interaction over Information, suggesting a preference for increasing engagement among their followers rather than simply serving as a conduit for training and nutrition advice.

Promotion. The increased interaction can spur revenue opportunities through the sales of tickets and merchandise (Williams \& Chinn, 2010). Professional sports leagues appear most proficient with these activities, using Facebook and Pinterest to create opportunities to sell products (Pronschinske et al., 2012; Waters et al., 
2011). Despite these opportunities, in this study only $2 \%$ of the CrossFit social media messages were promotional in nature. It would be expected that the CrossFit events and regions along with individual athletes would promote their own brands or activate their sponsorships through social media. The results indicated the CrossFit Games and regions had the most promotional messages, with $4 \%$ and 3\% of their messages featuring promotional content, respectively. While this limited activity represents a missed opportunity to connect with fans and create value for the CrossFit organizations and athletes, it may not be viewed as important currently for CrossFit marketing communications managers. Instead the focus may be on developing and growing their gym affiliates and members.

\section{Practical implications}

Of the four overall categories and three relationship-marketing activities, Information proved the overall favorite among the CrossFit groups. It is logical for a niche sport within a growth stage to demonstrate marketing communication behaviors that promote sport awareness and information sharing within its community. Interaction was the second most popular activity as the community, while still growing, exhibited familiarity and unique relationships with each other.

The groups seemed to delay Promotion activities in their current social media usage. As the community grows and the sport matures, the groups may wish to monetize their social media communications by peppering messages with relevant promotional content. In the meantime, the groups demonstrated a concentrated effort to take advantage of social media outlets, especially Facebook, to provide information, and Twitter, to interact with each other. These activities not only increase awareness about the sport as a whole, but also add value to the customer-CrossFit relationship. To achieve these relationship-marketing outcomes, the groups have utilized certain platforms for specific activities.

The current results indicate Twitter was the preferred platform in the CrossFit community. Overall, $62 \%$ of CrossFit community messages were found on Twitter. Interestingly, over $62 \%$ of the messages created by the boxes and female athletes were posted on Twitter. These 140-character exchanges may lend themselves to greater interaction among and across CrossFit members in comparison to Facebook and YouTube activity. As contemporary niche sports relay more on individual brand ambassadors, such as athletes, Twitter may be the preferred form of communication for these groups.

Conversely, the CrossFit regions displayed different usage preferences, where over $71 \%$ of their social media content was found on Facebook. This platform may have offered a better forum for delivering CrossFit organizational messages. To convey their intended message, posts sometimes exceeded the 140-character limit of Twitter, and thus Facebook represented a better format to deliver a richer, more detailed level of content. Likewise, YouTube was a viable option for the CrossFit Games to deliver information, and a variety of informative content was posted in this forum.

Yet rather than limiting themselves to a single platform per message, the groups leveraged the three to varying degrees. Providing a variety of messages across different forums, rather than simply relying on one form or another, can create benefits for organizations (Hambrick \& Mahoney, 2011).

\section{Limitations and future research}

The study has several limitations. First, the study examined the niche sport CrossFit. While the findings have application to niche sports in general, a study of other niche sports may have yielded differing results depending on the nature of each sport's social media use. Second, the study collected data across three social media platforms. The inclusion of other platforms such as Pinterest or Instagram may have provided different results. Finally, the study examined CrossFit from a more organizational perspective by including the CrossFit Games 
and other key groups. Exploring CrossFit fans and their social media usage in regard to the sport may have offered differing conclusions.

To address these limitations, future studies may include other niche sports and their use of social media among various platforms to expand the findings to a broader niche sports environment. Additional research in this area could also incorporate other platforms and groups. With the increasing popularity of newer tools - and more sports organizations incorporating them into their social media strategies-an exploration of these platforms could increase the understanding of how a variety of platforms can be best leveraged by a sport and its various constituents. Finally, a similar analysis may include fans as another sport community member. These followers may also be content creators, who share their comments and perspectives about the sports team/organization, athletes and sponsors. Including their social media messages may provide additional insights.

\section{REFERENCES}

Abeza, G., O'Reilly, N., \& Reid, I. (2013). Relationship marketing and social media in sport. International Journal of Sport Communication, 6, 120-142. DOI: 10.1123/ijsc.6.2.120.

Achauer, H. (2014). 209,585: Rise of the Open. Retrieved from http://games.crossfit.com/article/209585-rise-open

Benjamin, A.S. (2012). Using sport education to implement a CrossFit unit. Journal of Physical Education, Recreation \& Dance, 83, 42-48. DOI: 10.1080/07303084.2012.10598829.

Bennett, G., Henson, R.K., \& Zhang, J. (2012). Generation Y's perceptions of the action sports industry segment. Journal of Sport Management, 17, 95-115. DOI: 10.1123/jsm.17.2.95.

Bulmer, D., \& DiMauro, V. (2010). The new symbiosis of professional networks: Social media's impact on business and decision-making. Journal of New Communications Research, 4, 93-100.

Clavio, G., \& Kian, T.M. (2010). Uses and gratifications of a retired female athlete's Twitter followers. International Journal of Sport Communication, 3, 486-500. DOI: 10.1123/ijsc.3.4.485.

Clavio, G., \& Walsh, P. (2013). Dimensions of social media utilization among college sport fans. Communication \& Sport, 1, 2-22. DOI: 10.1177/2167479513480355.

Coddington, M., \& Holton, A. E. (2014). When the gates swing open: Examining network gatekeeping in a social media setting. Mass Communication and Society, 17, 236-257. DOI: 10.1080/15205436.2013.779717.

Frederick, E. L., Lim, C. H., Clavio, G., Pedersen, P. M., \& Burch, L. M. (2014). Choosing between the one-way or twoway street: An exploration of relationship promotion by professional athletes on Twitter. Communication \& Sport, 2, 8099. DOI: $10.1177 / 2167479512466387$.

Greenhalgh, G. P., Simmons, J. M., Hambrick, M. E., \& Greenwell, T. C. (2011). Spectator support: Examining the attributes that differentiate niche from mainstream sport. Sport Marketing Quarterly, 20, 41-52.

Grönroos, C. (2004). The relationship marketing process: Communication, interaction, dialogue, value. Journal of Business and Industrial Marketing, 19, 99-113. DOI: 10.1108/08858620410523981.

Hambrick, M.E., \& Kang, S.J. (2014). Pin it: exploring how professional sports organizations use Pinterest as a communications and relationship-marketing tool. Communication \& Sport.

DOI: $10.1177 / 2167479513518044$.

Hambrick, M.E., \& Mahoney, T.Q. (2011). "It's incredible - trust me": Exploring the role of celebrity athletes as marketers in online social networks. International Journal of Sport Management and Marketing, 10, 161-179. DOI: 10.1504/IJSMM.2011.044794.

Lombard, M., Snyder-Duch, J., \& Bracken, C.C. (2002). Content analysis in mass communication: Assessment and reporting of intercoder reliability. Human Communication Research, 28, 587-604. DOI: 10.1111/j.14682958.2002.tb00826.x.

Mahoney, T.Q., Hambrick, M.E., Svensson, P.G., \& Zimmerman, M.H. (2013). Examining emergent niche sports YouTube exposure through the lens of the Psychological Continuum Model. International Journal of Sport Marketing and Management, 13(3-4), 218-238. DOI: 10.1504/IJSMM.2013.059717.

Miloch, K.S., \& Lambrecht, K.W. (2006). Consumer awareness of sponsorship at grassroots sport events. Sport Marketing Quarterly, 15, 147-154. 
Miranda, F.J., Chamorro, A., Rubio, S., \& Rodriguez, O. (2014). Professional sports teams on social networks: A comparative study employing the Facebook Assessment Index. International Journal of Sport Communication, 7, 74-89. DOI: 10.1123/IJSC.2013-0097.

O'Hallarn, B., \& Shapiro, S. (2014). \#NBCFail: A qualitative review of the shared experience as a social movement. First Monday, 19. DOI: 10.5210/fm.v19i1.4760.

O'Shea, M., \& Alonso, A. D. (2011). Opportunity or obstacle? A preliminary study of professional sport organizations in the age of social media. International Journal of Sport Management and Marketing, 10,196-212. DOI: 10.1504/IJSMM.2011.044790.

Pedersen, P. M. (2014). A commentary on social media research from the perspective of a sport communication journal editor. Communication \& Sport, 2, 138-142. DOI: 10.1177/2167479514527428.

Pronschinske, M., Groza, M. D., \& Walker, M. (2012). Attracting Facebook "fans": The importance of authenticity and engagement as a social networking strategy for professional sport teams. Sport Marketing Quarterly, 21, $221-231$.

Puchan, H. (2004). Living "extreme": Adventure sports, media and commercialization. Journal of Communication Management, 9, 171-178. DOI: 10.1108/13632540510621588.

Rishe, P. (2011). Enhancing corporate productivity, community with group fitness programs: The Reebok-CrossFit paradigm. Forbes. Retrieved from http://www.forbes.com/sites/prishe/2011/10/22/enhancing-corporate-productivitycommunity-with-group-fitness-programs-the-reebok-crossfit-paradigm/.

Rozov, Z.E. (2008). Niche sports find a home—and fans—on the web. Revolution, 21.

Sanderson, J., \& Emmons, B. (2014). Extending and withholding forgiveness to Josh Hamilton: Exploring forgiveness within parasocial interaction. Communication and Sport, 2, 24-47. DOI: 10.1177/2167479513482306.

Wallace, L., Wilson, J., \& Miloch, K. (2011). Sporting Facebook: A content analysis of NCAA organizational sport pages and Big 12 Conference athletic department pages. International Journal of Sport Communication, 4, 422-444. DOI: 10.1123/ijsc.4.4.422.

Waters, R.D., Burke, K.A., Jackson, Z.H., \& Buning, J.D. (2011). Using stewardship to cultivate fandom online: Comparing how National Football League teams use their web sites and Facebook to engage their fans. International Journal of Sport Communication, 4, 163-177. DOI: 10.1123/ijsc.4.2.163.

Williams, J., \& Chinn, S. J. (2010). Meeting relationship-marketing goals through social media: A conceptual model for sport marketers. International Journal of Sport Communication, 3, 422-437. DOI: 10.1123/ijsc.3.4.422.

Zimmerman, M.H., Clavio, G.E., \& Lim, C. (2011). Set the agenda like Beckham: A professional sports league's use of YouTube to disseminate messages to its users. International Journal of Sport Management and Marketing, 10, 180-195. DOI: 10.1504/IJSMM.2011.044789.

\section{AUTHOR'S ADDRESS:}

\section{Chulhwan Choi}

Department of Golf Industry, College of Physical Education, Kyung Hee University

Seocheon-dong 1, Giheung-gu, Yongin-si

Gyeonggi-do 17104, Korea

E-mail: chulhwan.choi@khu.ac.kr

Received: 28 January 2019; Accepted: 28 February 2019 